\title{
Caracterização de Materiais: A Termodinâmica e suas aplicações no estudo da análise térmica de argilas
}

\author{
Characterization of Materials: Thermodynamics and its applications in the study of clay thermal \\ analysis
}

Caracterización de Materiales: Termodinámica y sus aplicaciones en el estudio del análisis térmico de arcilla

Recebido: 23/01/2021 | Revisado: 25/01/2021 | Aceito: 27/01/2021 | Publicado: 04/02/2021

Francisca das Chagas Oliveira

ORCID: https://orcid.org/0000-0002-6262-9125

Instituto Federal de Educação, Ciência e Tecnologia do Piauí, Brasil

E-mail: francisca.mat@hotmail.com

Rebeka Manuela Lobo Sousa

ORCID: https://orcid.org/0000-0002-8195-6447

Instituto Federal de Educação, Ciência e Tecnologia do Piauí, Brasil

E-mail:rebekamanuela28@gmail.com

Paulysendra Felipe Silva

ORCID: https://orcid.org/0000-0002-0129-8772

Instituto Federal de Educação, Ciência e Tecnologia do Piauí, Brasil

E-mail: sendra_102@hotmail.com

Phillype Dowglas Lopes

ORCID: https://orcid.org/0000-0002-4103-3883

Instituto Federal de Educação, Ciência e Tecnologia do Piauí, Brasil

E-mail: eng.phillype@hotmail.com

Rodolpho Carvalho Leite

ORCID: https://orcid.org/0000-0001-8554-1292

Instituto Federal de Educação, Ciência e Tecnologia do Piauí, Brasil

E-mail: rodolpho.leite@ifpi.edu.br

Maria de Fátima Salgado

ORCID: https://orcid.org/0000-0001-5571-9141

Instituto Federal de Educação, Ciência e Tecnologia do Piauí, Brasil

E-mail: mariadefatimasalgado@yahool.com.br

Gilvan Moreira da Paz

ORCID: https://orcid.org/0000-0002-6849-0320

Instituto Federal de Educação, Ciência e Tecnologia do Piauí, Brasil

E-mail:gilvan@ifpi.edu.br

Roberto Arruda Lima Soares

ORCID: https://orcid.org/0000-0003-1892-7499

Instituto Federal de Educação, Ciência e Tecnologia do Piauí, Brasil

E-mail: robertoarruda@ifpi.edu.br

\section{Resumo}

A termodinâmica está ligada à ciência dos materiais; o que significa a obtenção de novos materiais que tenham propriedades químicas e físicas bem definidas. A termodinâmica, podemos dizer, é uma das bases da engenharia de materiais, pois os processos de fabricação de novos materiais envolvem a transferência de calor e o trabalho para as matérias-primas. O objetivo deste artigo é apresentar as aplicações da termodinâmica no estudo de propriedades químicas e físicas bem definidas de materiais de argila para a obtenção de novos tipos de materiais por meio de revisão bibliográfica.

Palavras-chave: Termodinâmica; Argila; Caracterização; Termogravimétrica.

\begin{abstract}
Thermodynamics is linked to materials science; which studies means for obtaining new materials that have welldefined chemical and physical properties. Thermodynamics, we can say, is one of the bases of materials engineering, because the manufacturing processes of new materials involve the transfer of heat and work to the raw materials. The objective of this article is to present the applications of thermodynamics in the study of well-defined chemical and physical properties of clay materials to obtain new types of materials through a literature review.

Keywords: Thermodynamics; Clay; Characterization; Thermogravimetric.
\end{abstract}




\begin{abstract}
Resumen
La termodinámica está vinculada a la ciencia de los materiales; lo que significa obtener nuevos materiales que tienen propiedades químicas y físicas bien definidas. La termodinámica, podemos decir, es una de las bases de la ingeniería de materiales, ya que los procesos de fabricación de nuevos materiales implican la transferencia de calor y el trabajo para materias primas. El objetivo de este artículo es presentar las aplicaciones de la termodinámica en el estudio de propiedades químicas y físicas bien definidas de los materiales de arcilla para obtener nuevos tipos de materiales a través de la revisión bibliográfica.
\end{abstract}

Palabras clave: Termodinámica; Arcilla; Caracterización; Termogravimétrica.

\title{
1. Introdução
}

Sabemos que a Termodinâmica, também denominada de termologia, tem diversas aplicações para investigar as características apresentadas no material. Consegue descrever materiais puros, quanto compósitos (Lee,1991), blendas (Werlang,1998), cerâmicas avançadas (Berg, 1989), fazendo uso de uma pequena quantidade de variáveis a fim de torná-los funcionais, utilizando para descrever variáveis como: temperatura, pressão, volume e número de mols. Considerada uma das bases da engenharia dos materiais, pois os processos de fabricação de novos materiais envolvem a transferência de calor, trabalho e volumes para as matérias primas (Rodrigues, 2011).

Os materiais cerâmicos em seu processamento e caracterização, bem como o estudo de suas propriedades mecânicas proporcionam a fabricação de novos materiais para aplicações científicas e tecnológicas. Observa-se um crescente interesse dos pesquisadores no tocante ao desenvolvimento de novos materiais cerâmicos (George et al., 2000; Faria et al., 2005). Estas pesquisas vêm se destacando como fatores de qualidade, uma vez que cumprem um papel importante à durabilidade, por exemplo, determinando, assim, o tempo de vida útil do produto final (Akiyoshi et al., 2006; Pradère et al., 2006).

Os materiais cerâmicos são compostos usualmente por elementos químicos metálicos e não metálicos ligados por ligações iônicas e/ou covalentes A principal delas é a argila, um material natural, terroso e fino que, ao ser misturado com água, adquire plasticidade, tornando-se fácil de ser moldado (Dias,2013). São produzidos pela ação do calor, pois são submetidas ao cozimento e subsequente resfriamento.

Para Gaspar e Deblass, 1992 durante a caracterização da matéria prima, a identificação dos minerais presentes nas argilas, são pontos críticos na determinação e entendimento do comportamento físico ou físico-químico dos materiais, fatores fundamentais para a qualidade e informação das possíveis blendagens, aditivação e exploração racional. Pretende-se então, com o emprego da Termodinâmica estudar as características da argila através de levantamento bibliográfico sobre métodos de caracterização por análise térmica permitindo assim fabricação de peças cerâmicas de melhor qualidade como também contribuir para melhoria no processo produtivo.

\section{Revisão Bibliográfica}

\subsection{Argilas}

A definição de argila se dá em vários campos de estudo; historicamente em mineralogia ela é um material natural, de granulação fina (menor que $2 \mu \mathrm{m}$ ) e que apresenta certa plasticidade em contato com a água. Ainda são quimicamente especificadas quando formadas por silicatos, hidratados de alumínio, ferro e magnésio. São caracterizadas como argilomineral ou argilominerais (Luna \& Schuchardt, 1999).

A argila é facilmente dispersa em água ou em outros solventes, podendo formar suspensões estáveis ou instáveis, diretamente ligada às propriedades físicas e químicas. Um dos fatores que pode ser levado em consideração é a plasticidade, que define como uma propriedade do material úmido que fica deformado (sem romper) pela aplicação de tensão, sendo que a deformação permanece quando a tensão aplicada é retirada (Santos,1975). 
As argilas podem ser também classificadas conforme a quantidade de colóides: as gordas são muito plásticas, devido à alumina deformam-se muito no processo de cozimento; as magras que possuem excesso de sílica são mais porosas e frágeis (Sousa, 2013).

Os principais tipos de argilas encontradas na natureza são: as argilas fluviais que são extremamente abundantes geralmente utilizadas em cerâmica vermelha; as argilas de estuários que contêm camadas ou áreas de laminação grossa, além de resíduos orgânicos de pântanos inter-laminados em camadas argilosas; as argilas de pântanos que são geralmente muito plásticas bastante puras e ricas em caulinitas e matéria orgânica; as argilas de cor de cozimento branca como os caulins e argilas plásticas utilizadas para a fabricação de pisos e azulejos; as argilas refratárias que são os caulins, argilas refratárias e argilas altamente aluminosas utilizada na confecção de tijolos refratários; e as argilas para materiais cerâmicos estruturais, amarelas ou vermelhas que são as argilas encontradas para a fabricação de manilhas, blocos e telhas (Sousa, 2013).

Conforme Figueiredo (2010), quantidades enormes de argilas são encontradas em solos brasileiros; desta forma, não é necessária a importação para a produção de materiais oriundos desta matéria-prima. O Maranhão apresenta pontos específicos e localidades que apresentam em abundância esse material. Sendo essas argilas: esmectitas, caulinitas, montmorilonita, hematitas, goetitas, entre outras.

Outro estado de produção significativa de produtos oriundos de argila é o Piauí apresenta uma importância para a economia, sendo o setor um grande gerador de empregos no Estado. Configura-se como uma referência regional de produto cerâmico de qualidade, principalmente as telhas prensadas, que estão entre as melhores do País. O pólo cerâmico de maior importância do Piauí está localizado na região da capital, Teresina, sendo composto por 24 cerâmicas e é um dos mais importantes da região Nordeste, constituindo-se em um centro exportador de produtos cerâmicos de queima vermelha para diversos estados do Brasil. Essa região possui grandes jazidas de argila de qualidade para cerâmica vermelha, principalmente nas margens dos rios Parnaíba e Poty, sendo responsável por 70\% da extração de argila do Estado. Beneficia-se também dessas jazidas, cerâmicas localizadas na cidade vizinha Timon, no estado do Maranhão (CEPRO, 2005).

Para Sousa et al. (2000), as argilas são empregadas numa série de produtos acabados, por possuir propriedades adequadas, pela abundância e por ser de fácil manuseio. Apresentam poder adsorvente, podem ser empregadas como peneiras moleculares, como agentes descorantes e clarificantes de óleos vegetais e minerais, como suportes catalíticos, como agente de filtração, como adsorventes de óleos em água, etc. Entretanto, seu uso na adsorção depende de diversos fatores, tais como pH, tipo e concentração do metal adsorvido, tempo de adsorção, além das características da argila a ser usada (Maia et al.,2000).

\subsection{Termodinâmica - principais técnicas}

A Termodinâmica estuda fenômenos e sistemas físicos complexos em que podem ocorrer trocas de calor, transformações de energia e variações de temperatura, equilíbrio térmico, conservação de energia para processos termodinâmicos, entropia e pôr fim a entropia de um sistema se aproxima de um valor constante conforme sua temperatura se aproxima do zero absoluto. "Toda vez que você dirige um carro, liga um ar condicionado ou usa um eletrodoméstico, você está usufruindo dos benefícios práticos da termodinâmica, o estudo das relações envolvendo calor, trabalho mecânico e outros aspectos da energia ou conversão entre tipos de energia." (Young, 2004).

Os engenheiros fazem uso dos princípios básicos da termodinâmica e de outras ciências na engenharia, tal qual a mecânica e eletromagnetismo, para analisar e projetar materiais com novas funcionalidades visando atender aos anseios da humanidade. Durante todo o século XX, foram aplicadas soluções de engenharia utilizando-se da termodinâmica, as quais ajudaram a abrir caminho para melhorias consideráveis na vida do ser humano, com importantes avanços em áreas significativas, como a aeronáutica, viagens espaciais, transporte em superfície, geração e transmissão de eletricidade, construções com sistemas de refrigeração e aquecimento, e melhorias nas práticas médicas (Moran et al., 2013). 
Segundo Castro et al. (2010), a termodinâmica fornece a base para organizar informações de como a matéria se comporta:

- Identifica as propriedades científica e tecnologicamente importantes dos sistemas, para um grande número de aplicações.

- Identifica o subconjunto dessas propriedades suficiente para calcular todas as demais.

- Essas propriedades são medidas ou calculadas em laboratórios ao redor do mundo, e são organizadas em bancos de dados, desde a época de Gibbs.

A termodinâmica fornece então as relações entre os dados dos bancos de dados e as propriedades necessárias para prever o comportamento da matéria.

Diante da necessidade de conhecimento das propriedades, ao longo dos anos foram sendo desenvolvidos métodos de análise térmica. As análises térmicas são interdisciplinares, sendo importantes em vários setores, dentre os quais podemos destacar: Química, Metalurgia, Cerâmica, Geologia, Mineralogia, e Oceanografia, Botânica, Agronomia, Ecologia, Tecnologia em Química e Tecnologia de Alimentos (Castro et al. 2010). No Quadro 1 estão técnicas e a propriedade medida em cada uma e suas respectivas aplicações.

Quadro 1. Termodinâmica -Principais técnicas e suas propriedades.

\begin{tabular}{|c|c|c|c|}
\hline TÉCNICA & SIGLA & $\begin{array}{c}\text { PROPRIEDADE DE } \\
\text { MASSA }\end{array}$ & USOS \\
\hline $\begin{array}{l}\text { Análise } \\
\text { Termogravimétrica }\end{array}$ & TGA & Massa & Decomposição \\
\hline $\begin{array}{l}\text { Termogravimetria } \\
\text { Derivada }\end{array}$ & DTG & Massa & $\begin{array}{l}\text { Desidratação } \\
\text { Oxidação }\end{array}$ \\
\hline $\begin{array}{l}\text { Análise Térmica } \\
\text { Diferencial }\end{array}$ & DTA & Temperatura & $\begin{array}{l}\text { Mudanças de fase } \\
\text { Reações }\end{array}$ \\
\hline $\begin{array}{l}\text { Calorimetria } \\
\text { Exploratória } \\
\text { Diferencial }\end{array}$ & DSC & Entalpia & $\begin{array}{l}\text { Capacidade de calor } \\
\text { Mudança de fase } \\
\text { Reações } \\
\text { Calorimetria }\end{array}$ \\
\hline Análise Termomecânica & TMA & Deformação & $\begin{array}{l}\text { Mudanças mecânicas } \\
\text { Expansão }\end{array}$ \\
\hline $\begin{array}{l}\text { Análise Dinâmico- } \\
\text { Mecânica }\end{array}$ & DMA & $\begin{array}{l}\text { Propriedades } \\
\text { mecânicas }\end{array}$ & $\begin{array}{l}\text { Mudança de fase } \\
\text { Cura do polímero }\end{array}$ \\
\hline Análise de gás envolvido & EGA & Gases & Decomposição \\
\hline Termoptometria & - & Ótica & $\begin{array}{l}\text { Mudança de fase } \\
\text { Reações de superfície } \\
\text { Mudanças de } \\
\text { coloração }\end{array}$ \\
\hline
\end{tabular}

Fonte: Castro et al. (2010). 
As principais técnicas difundidas e utilizadas são: análise termogravimétrica (TGA), termogravimétrica derivada (DTG), análise térmica diferencial (DTA), calorimetria exploratória diferencial (DSC), análise termomecânica (TMA), análise dinâmico-mecânica (DMA), análise de gás envolvido (EGA) e Termoptometria (Castro et al. 2010).

\section{Metodologia}

Para o desenvolvimento deste trabalho analisou-se dados já concluídos através de pesquisas bibliográficas. O levantamento dessas informações foi realizado no google acadêmico e portal de periódicos da CAPES, admitindo as publicações até 2019. Dessa forma reuniu-se bibliografias sobre as principais abordagens teóricas metodológicas publicadas, com destaque para as discussões sobre Termodinâmica. A coleta dos dados ocorreu através de leitura do resumo para verificar se a obra consultada era de interesse para seleção de ideias que possibilitaram atingir o objetivo da pesquisa. Ao final foi realizada a síntese dos principais resultados encontrados. A consistência dos trabalhos destacados foi realizada por análise na literatura citada e posteriores.

\section{Resultados e Discussão}

Apresentaremos neste trabalho análises termodinâmicas aplicadas na argila para acompanhar os resultados da variação de da amostra em relação a temperatura.

\subsection{Análise 01}

O trabalho realizado por Maia et al. (2020), tinha por objetivo identificar e qualificar a composição mineralógica e comportamento térmico das argilas dos depósitos aluvionares do alto Rio Sururiú, extraidas da localidade próxima à MS 306, que compõe a massa cerâmica da industria da região para fabricação de tijolos furados, este trabalho visa contribuir para o estudo de argilas da cidade de Costa Rica no estado de Mato Grosso do Sul. As matérias primas amostradas, estavam sendo utilizadas comercialmente por cerâmicas/olarias da região, onde eram fabricados produtos de cerâmica estrutural para aplicações na construção civil e para isso foram utilizadas as seguintes técnicas de caracterização de tal forma a determinar a composição mineralógica e química, identificando os principais argilominerais e minerais de argila presentes, assim como determinar as temperaturas dos possíveis eventos térmicos e as mudanças de propriedade física ou química em função da temperatura de aquecimento: análise química, análise térmica diferencial (DTA), calorimetria exploratória (DSC), análise termogravimétrica (TG), análise termomecânica (TMA). As amostras foram moídas a úmido em um moinho de bolas centrífugo Retsch e peneiradas até uma granulometria passante em peneira de malha 100 Tyler/Mesh para os ensaios de análise térmica, peneira 150 Tyler/Mesh para os ensaios de análise química. As análises termogravimétricas foram realizadas utilizando o equipamento Shimadzu TGA-50, em cadinho de alumina com aproximadamente $30 \mathrm{mg}$ de amostra. As análises de calorimetria exploratória diferencial foram realizadas utilizando equipamento Shimadzu DSC-50, usando cadinhos de alumina como referência e porta amostra, estando o cadinho de referência vazio, utilizando aproximadamente $30 \mathrm{mg}$ em cada análise. As análises termomecânicas foram realizadas utilizando o equipamento Shimadzu TGA-50H, em corpos de prova de aproximadamente 6 a $8 \mathrm{~mm}$ de comprimento, moldados por prensagem manual no estado plástico, sendo que a carga utilizada no equipamento foi de $10 \mathrm{~g}$. Na análise térmica diferencial usa-se cadinho de alumina com aproximadamente 100mg de amostra, utilizando o equipamento DTA-50. Todas as análises térmicas foram realizadas com taxa de aquecimento de $10^{\circ} \mathrm{C} /$ min e atmosfera de ar. Através das curvas TMA (Figura 1), TG (Figura 2), DSC (Figura 3) e DTA (Figura 4), referentes à amostra de Costa Rica (CR) e Caulim do Rio Grande do Sul (CERGS), podemos identificar uma reação endotérmica com perda de massa e contração entre a temperatura ambiente e $130^{\circ} \mathrm{C}$, devido à eliminação de água livre $(\Delta \mathrm{m} \cong 3,4 \%)$. 
Figura 1. Curvas da análise TMA (termomecânica) das argilas CR e CRGS.

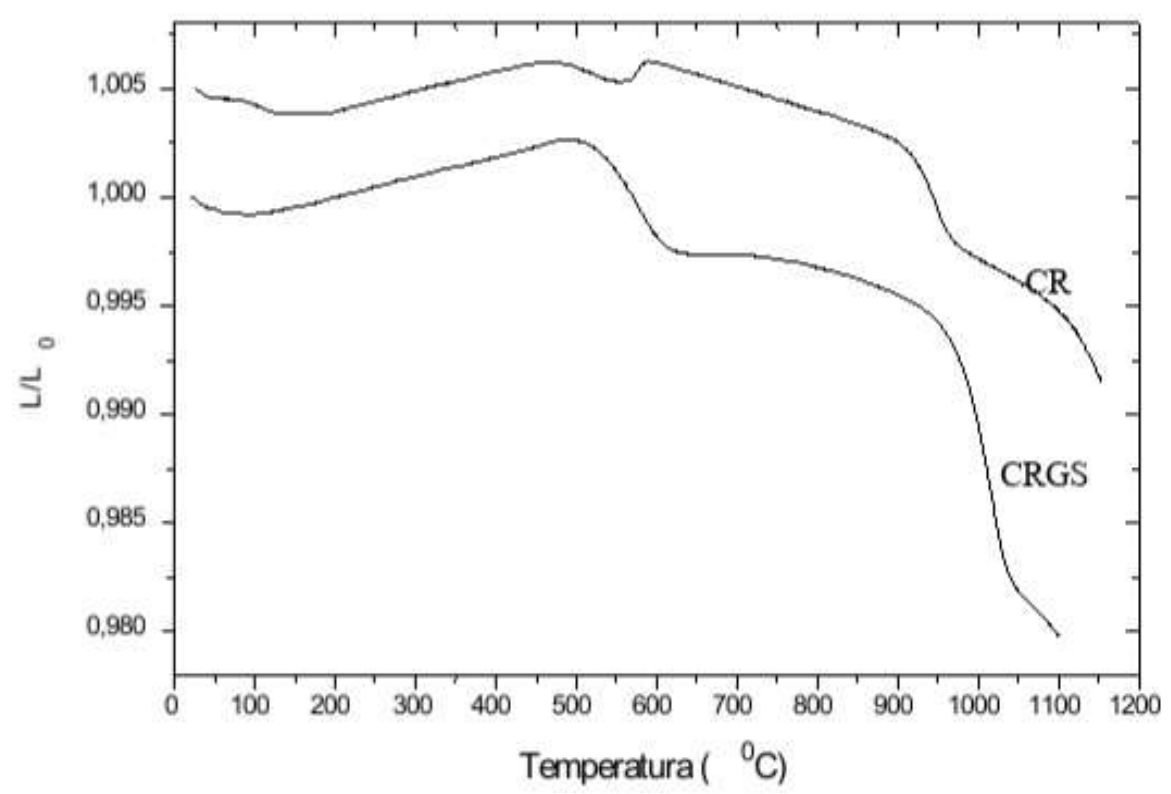

Fonte: Maia et al. (2000).

Figura 2. Curvas da análise TG (termogravimétrica) das argilas CR e CRGS.

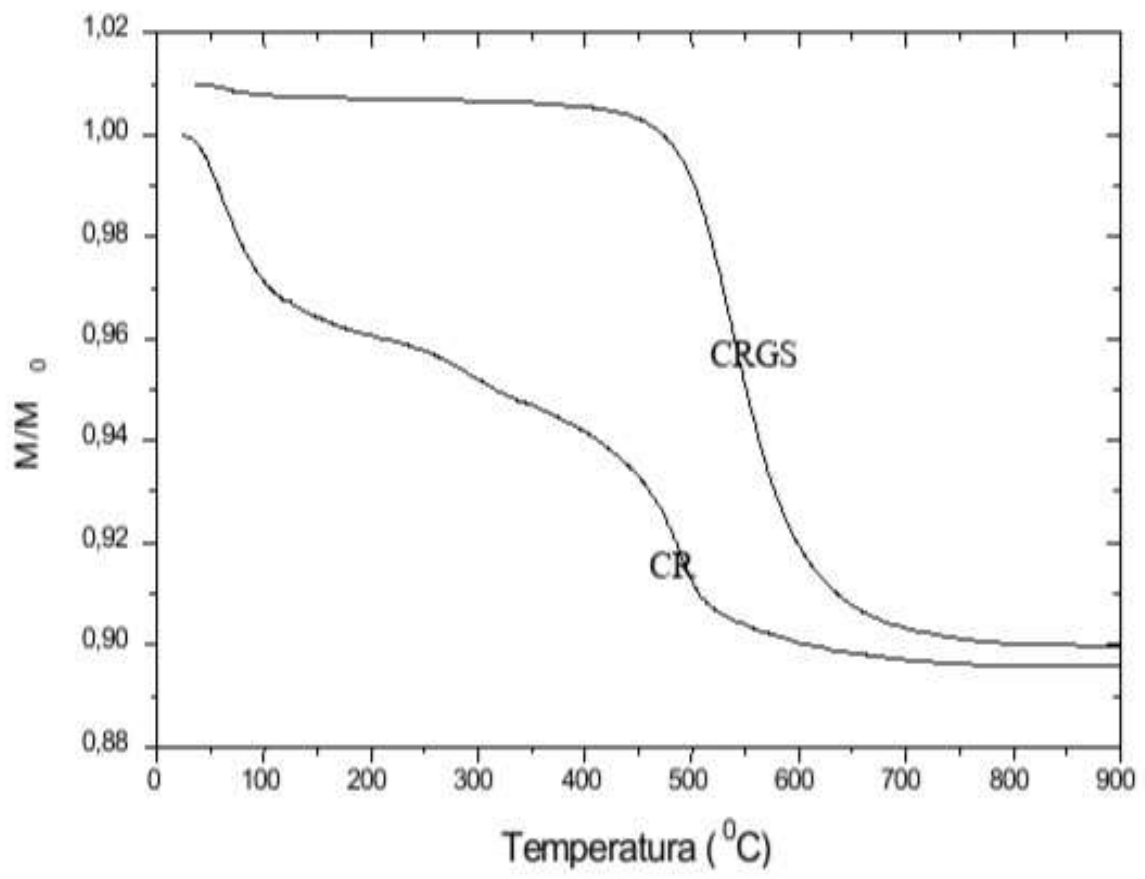

Fonte: Maia et al. (2000). 
Figura 3. Curvas da análise DSC (calorimetria exploratória) das argilas CR e CRGS.

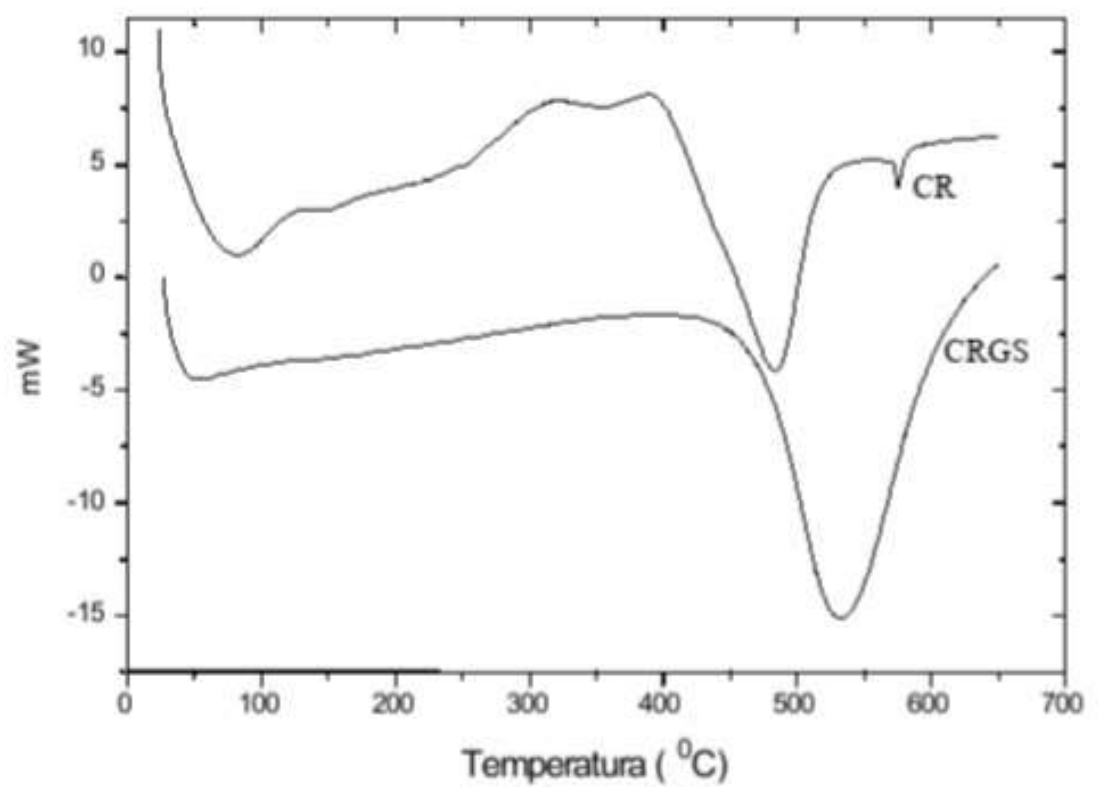

Fonte: Maia et al. (2000).

Figura 4. Curvas da análise DTA (térmica diferencial) da argila CR.

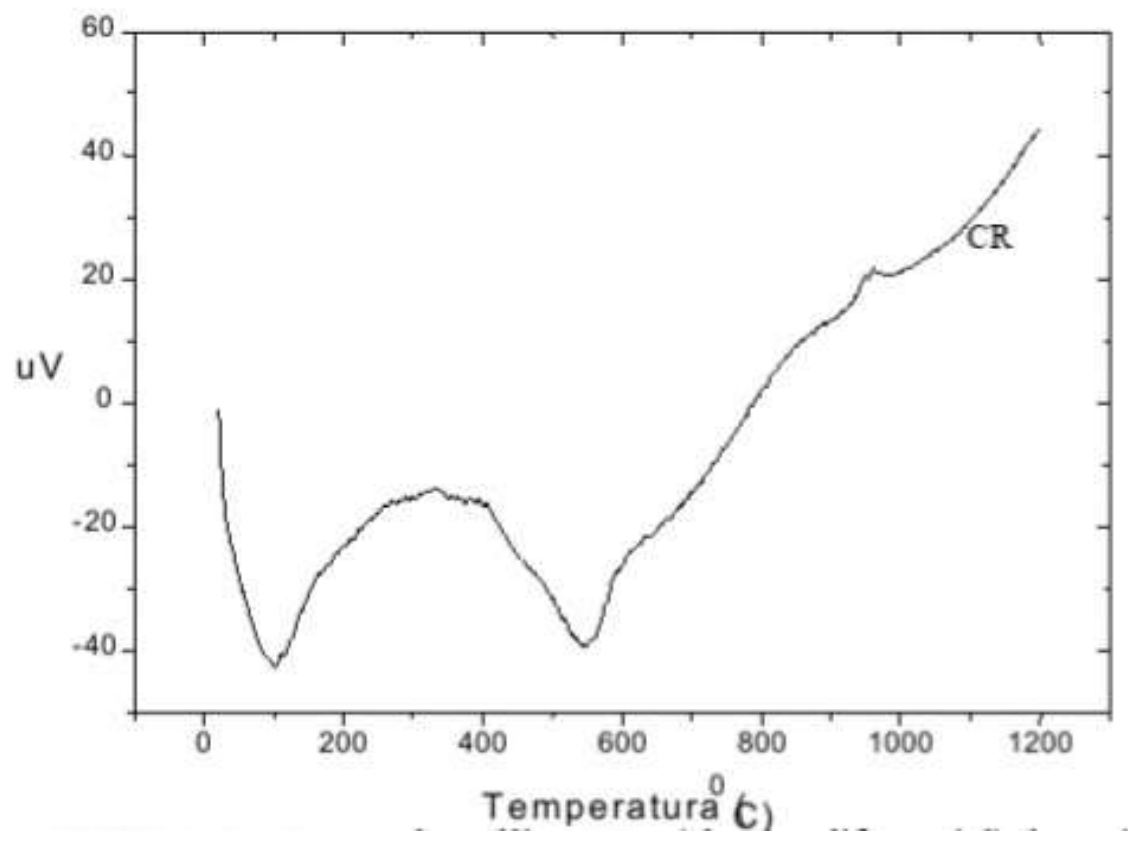

Fonte: Maia et al. (2000).

Entre $130^{\circ} \mathrm{C}$ e $180^{\circ} \mathrm{C}$, temos outra reação endotérmica com perda de massa (Dm @ 0,4\%), provavelmente devido à eliminação de água de estrutura da Ilita/Mica. Entre $180^{\circ} \mathrm{C}$ e $400^{\circ} \mathrm{C}$, temos reações exotérmicas com perda de massa (Dm@2,0\%), (Figuras 2 e 3), possivelmente devido à matéria orgânica e sulfetos presentes na amostra. $\mathrm{Na}$ faixa de $400^{\circ} \mathrm{C}$ e $600^{\circ} \mathrm{C}$, ocorrem reações endotérmicas, com perda de massa (Dm@4,1\%), devido à desidroxilação (OH) dos argilominerais. Nessa reação a argila CR precisou de DH @ -105,0J/g, quanto maior a presença do argilomineral caulinita em relação ao 
argilomineral ilita/mica, maior o DH. A amostra CRGS possui maior concentração de caulinita que a amostra CR, conforme Tabelas IV e V, entretanto a amostra CRGS precisou de DH @ -271,0J/g, com perda de massa 2 vezes maior que a da argila CR. Essas reações são acompanhadas de uma mudança no coeficiente de dilatação com contração nas amostras CRGS e CR (Figura 1). A eliminação da água da estrutura da caulinita acontece com a mudança do reticulado cristalino. Assim se verifica a contração relativa à reação endotérmica na desidroxilação da caulinita (Maia et al.,2000).

Em aproximadamente $575^{\circ} \mathrm{C}$, observamos uma reação endotérmica, acompanhada de dilatação (Figuras 1 e 3), devido à transição do quartzo livre presente na amostra, o quartzo muda sua estrutura cristalina da fase a para a fase b. Essa reação é reversível e ocorre por ocasião do resfriamento, com contração e calor liberado. O calor liberado na amostra CR foi maior que o liberado na amostra CRGS, devido à maior concentração de quartzo livre. Entre $600^{\circ} \mathrm{C} \mathrm{e} 900^{\circ} \mathrm{C}$, temos uma pequena perda de massa talvez em consequiência da descarbonatação, com contração lenta, o coeficiente de dilatação encontrado foi -11,1.106/K para a amostra CR e -5,6.10-6/K para a amostra CRGS. Entre $900^{\circ} \mathrm{C}$ e $1000^{\circ} \mathrm{C}$ as amostras $\mathrm{CR}$ e CRGS contraíram acentuadamente. Nesta faixa de temperatura há, no caso da caulinita (nesta temperatura metacaulinita), a destruição do retículo cristalino com a formação da fase espinélio (2Al2O3.3SiO2), com separação da sílica amorfa. A curva de DTA (Figura 4) apresenta reação exotérmica com pico a $945^{\circ} \mathrm{C}$ devido à recristalização da metacaulinita. Entre $1000^{\circ} \mathrm{Ce} 1200^{\circ} \mathrm{C}$, observamos a alteração no coeficiente de dilatação, diminuindo acentuadamente a contração em torno de $1100^{\circ} \mathrm{C}$. Acima de $1100^{\circ} \mathrm{C}$ a rápida contração que ocorre na amostra de argila indica o processo de sinterização que depende da quantidade de fundentes, mas não está diretamente relacionado às reações químicas que ocorrem nessas temperaturas, entretanto esses efeitos podem ocorrer simultaneamente (Maia et al.,2000).

\subsection{Análise 02}

Oliveira et al. (2010), se propõe a caracterizar uma argila encontrada na região de Vitória da Conquista no Sudoeste da Bahia, para avaliar a sua aplicação nas Indústrias Cerâmicas na fabricação de produtos cerâmicos aplicados na construção civil em geral. A amostra de argila moída foi caracterizada por meio das seguintes técnicas: Análise Térmica: As análises térmicas são métodos muito úteis na caracterização de argilas. A análise de calorimetria exploratória diferencial (DSC) e a análise termogravimétrica (TG) foram realizadas de acordo com as normas de caracterização térmica de materiais (ASTM D3417 e ASTM D3418) em equipamento DTA/TGA/DSC da NETZSCH modelo STA409C. A razão de aquecimento utilizada foi de $10{ }^{\circ} \mathrm{C} / \mathrm{min}$, em atmosfera de nitrogênio. As temperaturas inicial e final da análise foram $20^{\circ} \mathrm{C} \mathrm{e} 1300^{\circ} \mathrm{C}$, respectivamente. Difração de raios-X: A difração de raios X pelo método do pó é uma técnica muito importante na caracterização de materiais cerâmicos cristalinos e argilas. A amostra de argila moída foi analisada utilizando um difratômetro de raios-X Rigaku MultiFlex com monocromador. As condições experimentais foram: $40 \mathrm{kV}, 20 \mathrm{~mA}, 20^{\circ} \leq 2 \theta \leq 80^{\circ}, \Delta 2 \theta=$ $0.02^{\circ}, \lambda_{\text {cuK } \alpha}$, fenda de divergência $=0.5^{\circ}$, fenda de recepção $=0.3 \mathrm{~mm}$ e tempo de contagem $6 \mathrm{~s}$. Os dados obtidos foram comparados com os dados do ICDD.

Para Oliveira et al. (2010), os resultados obtidos para a análise térmica da amostra mostram a curva característica de um caulim com um pico endotérmico a aproximadamente $500^{\circ} \mathrm{C}$ caracterizando a transformação de caulinita em metacaulinita e um pico exotérmico mais agudo a $965^{\circ} \mathrm{C}$ provavelmente devido a transformação da metacaulinita em mulita. Também foi observado um pico a $573^{\circ} \mathrm{C}$ provavelmente devido a transformação de quartzo alfa para quartzo beta, mostrando a presença de quartzo na argila, conforme a Figura 5. 
Research, Society and Development, v. 10, n. 1, e6510212284, 2021

(CC BY 4.0) | ISSN 2525-3409 | DOI: http://dx.doi.org/10.33448/rsd-v10i1.12284

Figura 5. Gráfico DSC (Calorimetria Exploratória Diferencial) da amostra de argila.

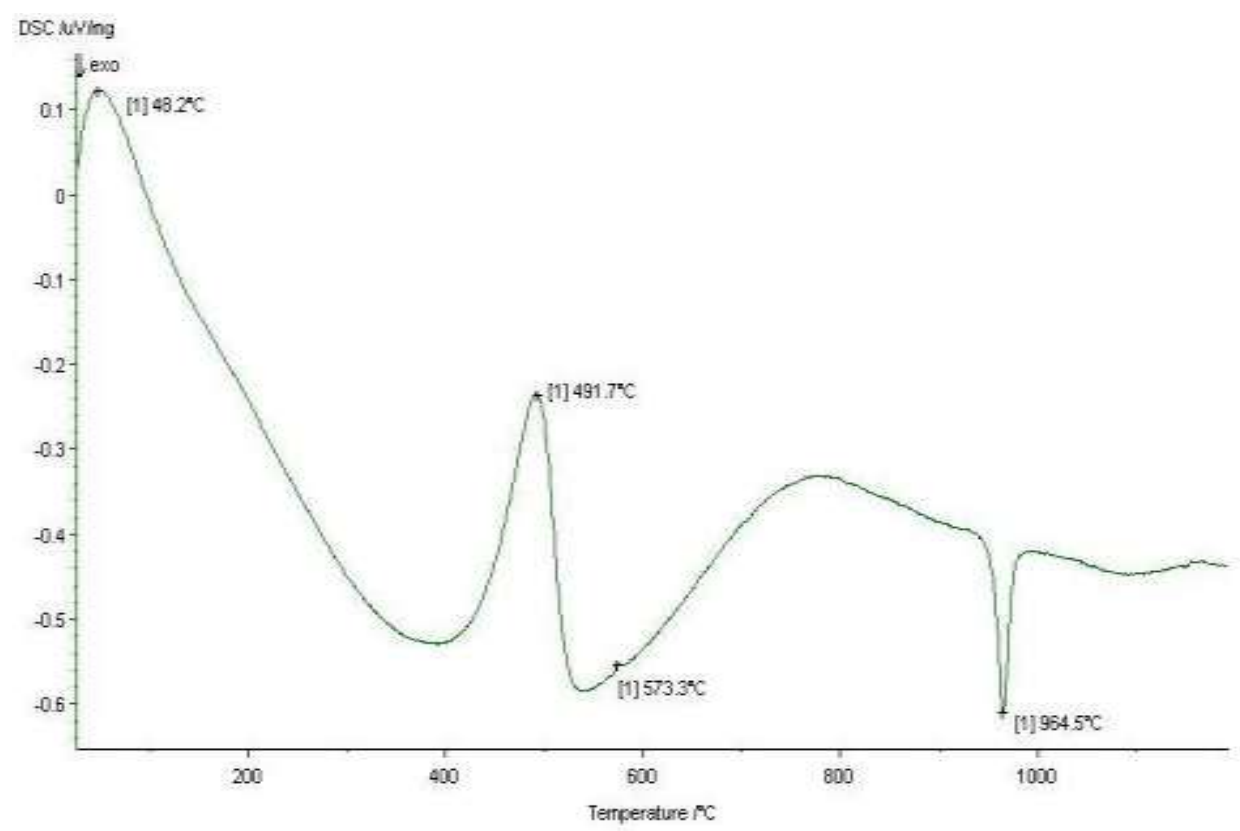

Fonte: Oliveira et al. (2000).

A Figura 6 apresenta a análise termogravimétrica mostrando a perda de massa característica da desidroxilação (em torno de $500^{\circ} \mathrm{C}$ ) e uma pequena perda de massa em uma faixa de temperatura mais baixa, provavelmente devido a perda de água e queima da matéria orgânica.

Figura 6. Gráfico TG (Análise Termogravimétrica).

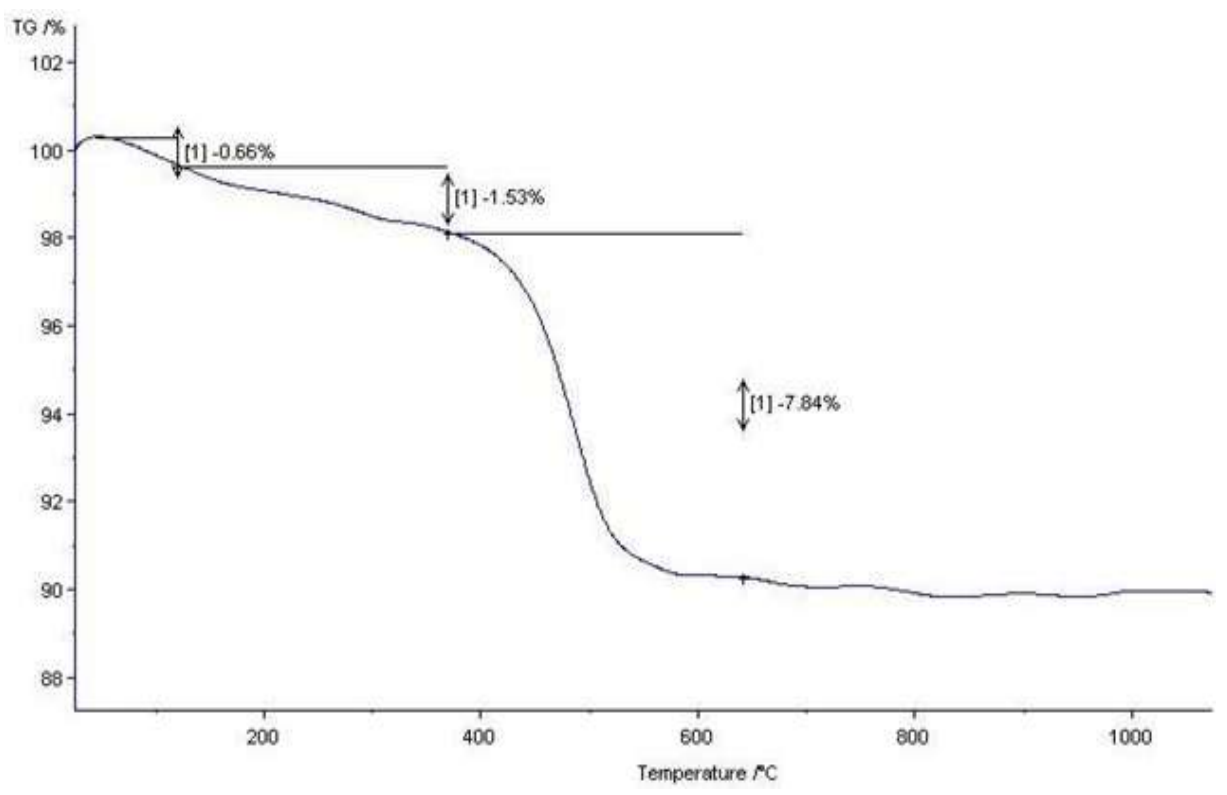

Fonte: Oliveira et al. (2000). 


\subsection{Análise 03}

Gonçalves (2015), realizou em suas pesquisas a síntese, caracterização e avaliação técnica de catalisadores heterogêneos a base de argilas maranhense dopada com estanho e nióbio. Para a dopagem da argila foi empregado o método de precursores poliméricos. A amostra da argila foi extraída no município de Grajaú no Estado do Maranhão, as amostras apresentaram uma grande quantidade de impurezas devido ao processo de formação dessas argilas; como exemplos: matéria orgânica, sais solúveis, partículas de quartzo, pirita, mica, calcita, dolomita, gipsita, aluminita e outros minerais residuais.

Análise Térmica (TGA) o estudo da perda de massa dos suportes catalíticos foi analisado por termogravimétria usando um equipamento/modelo TGA 4000, marca Perkin Elmer, com cadinho de porcelana, atmosfera dinâmica de N2 (20 $\mathrm{mL} / \mathrm{min}$ ) e Ar sintético (20 mL/min), em uma taxa de aquecimento de $10^{\circ} \mathrm{C} / \mathrm{min}$, na faixa de temperatura de 30 a $900{ }^{\circ} \mathrm{C}$. Os experimentos foram realizados utilizando uma faixa de $10 \mathrm{mg}$ das amostras. Sendo utilizado para a identificação de perda de massa a partir da temperatura. A primeira etapa da perda de massa é a partir da vaporização da água que se encontra presente na amostra, em seguida, são liberados os gases que saem naturalmente da amostra, depois a decomposição da matéria orgânica. Esta técnica realizou-se na Central Analítica do Departamento de Engenharia Química da Universidade Federal do Paraná (Gonçalves, 2015).

A análise térmica utilizada nas amostras foi a análise termogravimétrica TGA, onde foi avaliada a relação de perda de massa $(\%)$ em função da temperatura $\left({ }^{\circ} \mathrm{C}\right)$ e a estabilidade térmica das amostras Tabela 1.

Tabela 1. Análise termogravimétrica das amostras.

\begin{tabular}{lc} 
Amostras & Perda de massa \\
\hline Argila Natural & $12,47 \%$ \\
Argila Ativada & $12,85 \%$ \\
Argila calcinada & $18,03 \%$ \\
Argila+SnO2 & $5,23 \%$ \\
Argila+SnO2+1\%Nb & $4,73 \%$ \\
Argila+SnO2+5\%Nb & $4,47 \%$ \\
Argila+SnO2+10\% Nb & $5,01 \%$ \\
Argila+Nb2O5 & $5,69 \%$ \\
SnO2 & $2,38 \%$ \\
Nb2O5 & $3,43 \%$ \\
SnO2 $+1 \% \mathrm{Nb} 2 \mathrm{O} 5$ & $4,34 \%$ \\
$\mathrm{SnO} 2+5 \% \mathrm{Nb} 2 \mathrm{O} 5$ & $3,19 \%$ \\
$\mathrm{SnO} 2+10 \% \mathrm{Nb} 2 \mathrm{O}$ & $3,22 \%$ \\
\hline
\end{tabular}

Fonte: Gonçalves (2015).

Conforme Gonçalves (2015), às argilas sem dopagem foram as que obtiveram maior perda de massa, conforme apresentado na Tabela 1. Tendo a argila calcinada (Figura 7) a maior perda que é de 18,03\%, porém, com apenas a perda de $3,4 \%$ a temperatura de $160{ }^{\circ} \mathrm{C}$. Já a argila ativada (Figura 8) obteve a maior perda de massa até a temperatura de $160{ }^{\circ} \mathrm{C}$ sendo caracterizada perda de água que foi de $6,74 \%$ enquanto sua perda total de massa foi de $12,85 \%$. 
Figura 7. Análise termogravimétrica da argila calcinada.

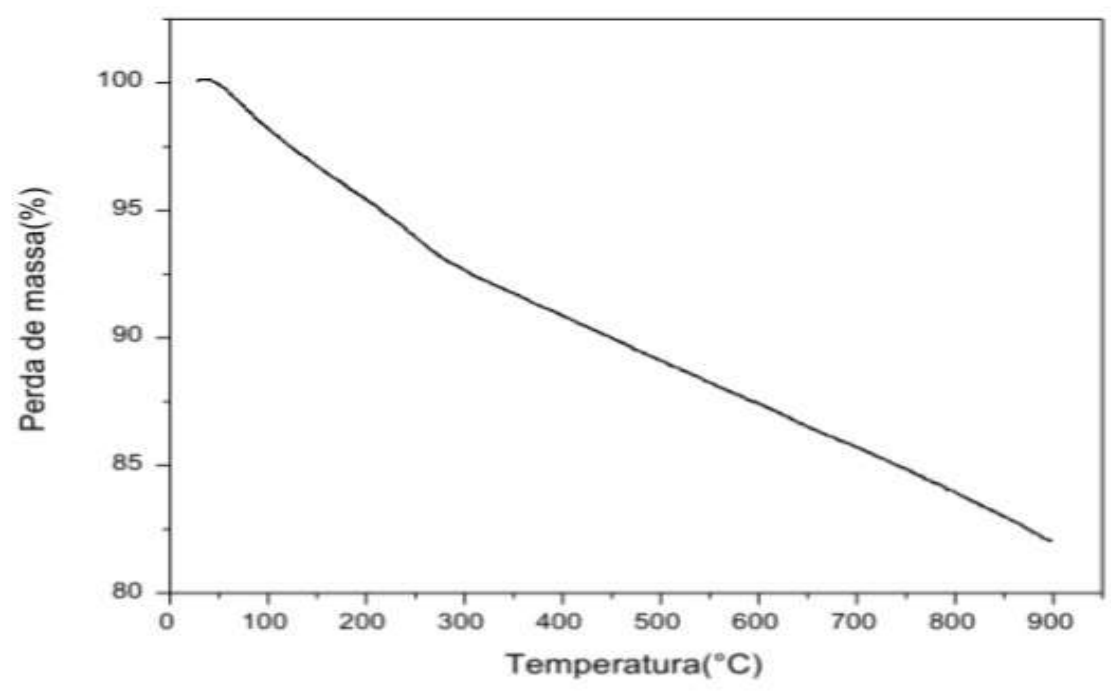

Fonte: Gonçalves (2015).

Figura 8. Análise termogravimétrica da argila ativada.

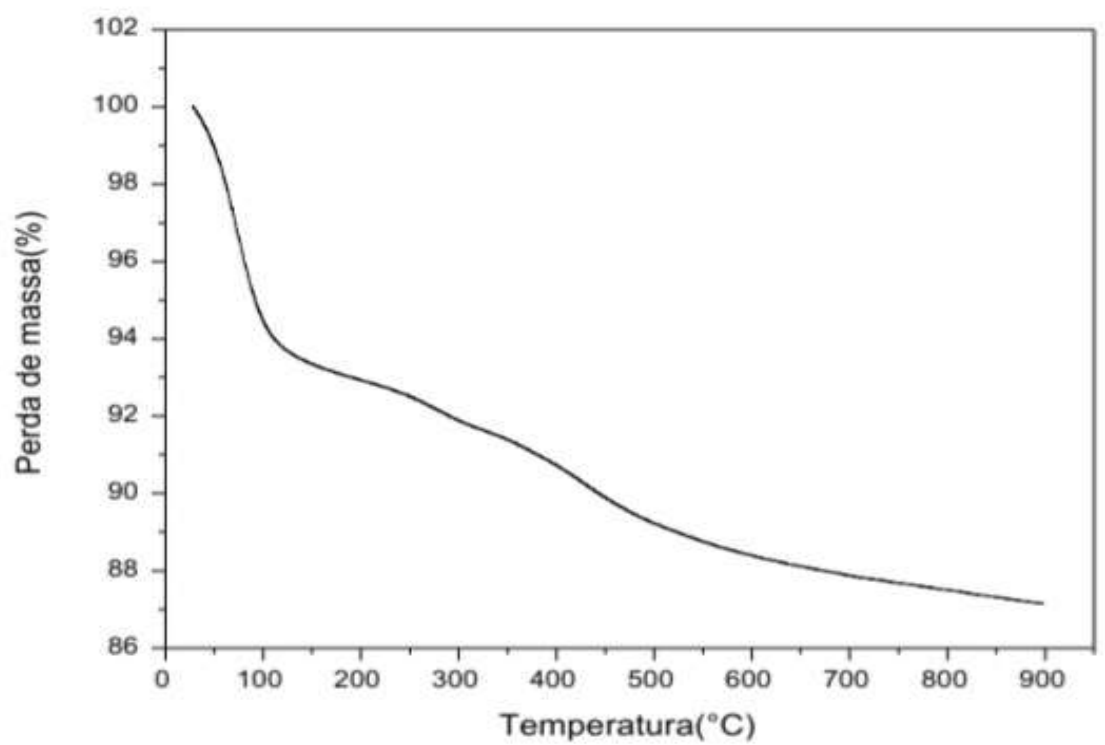

Fonte: Gonçalves (2015).

Até os $160{ }^{\circ} \mathrm{C}$ podemos perceber a perda de massa devido às moléculas de água intralamelar e na superfície. A partir daí começa a perda de massa que se encontra relacionada à matéria orgânica. $\mathrm{E}$ acima de $580^{\circ} \mathrm{C}$ identifica-se a perda atribuída a desidroxilação dos hidróxidos de alumínio, modificando a rede cristalina do material inorgânico (Figueiredo, 2010; Sales, 2009).

A perda de massa ainda é maior nas amostras que possuem argila como suporte para o metal, sendo a argila dopada com o nióbio (Figura 9) a maior perda que é de 5,69\% e a menor foi o óxido de estanho puro, obtendo apenas $2,58 \%$ (Figura 
10). Sendo que todas as amostras que contém menos de $1 \%$ de perda de massa até os $160{ }^{\circ} \mathrm{C}$, as demais análises se encontram em anexo (Gonçalves, 2015).

Figura 9. Análise termogravimétrica da argila + oxido de nióbio.

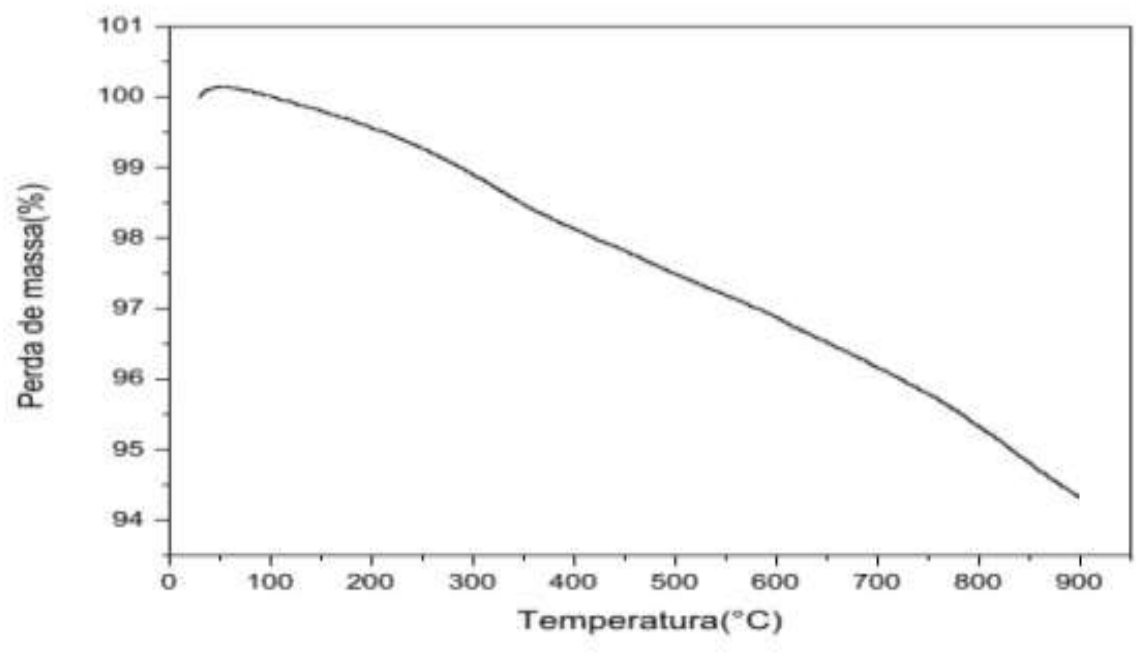

Fonte: Gonçalves (2015).

Figura 10. Análise termogravimétrica da argila +dióxido de estanho.

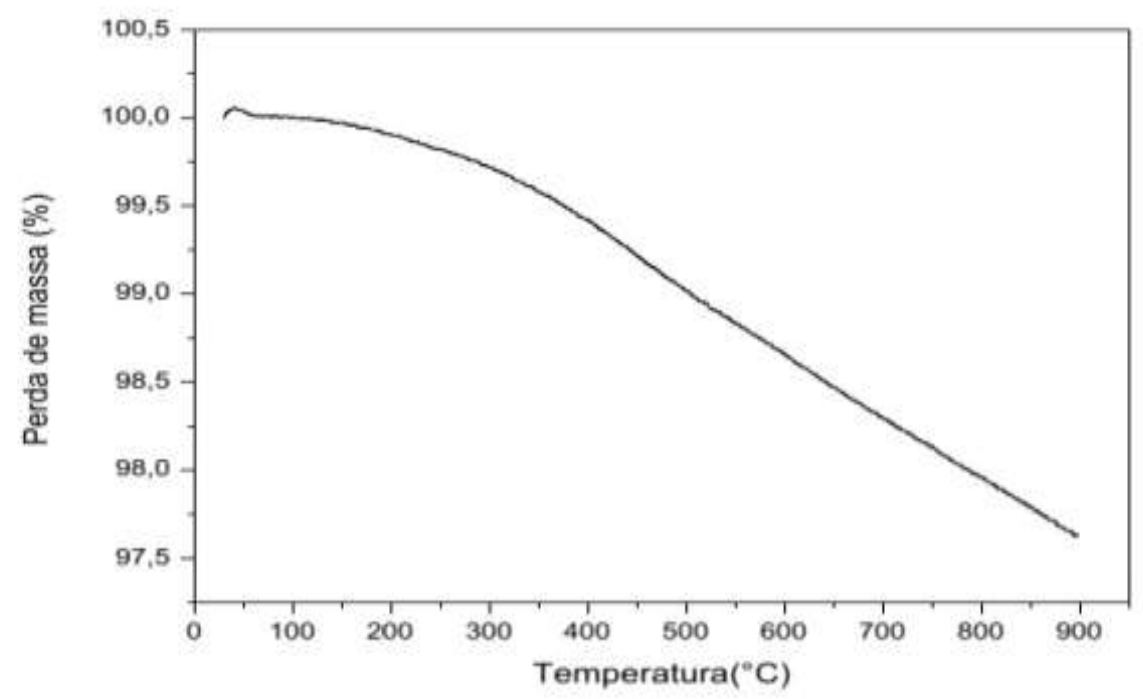

Fonte: Gonçalves (2015).

No caso das amostras que possuem o óxido de estanho na sua composição mantém-se com a perda de massa inferior a $5,5 \%$, tendo uma boa estabilidade térmica a altas temperaturas. Com o perfil da amostra na análise termogravimétrica TGA pode se observar que com a elevação da temperatura de tratamento até $550{ }^{\circ} \mathrm{C}$ a um aumento de acidez, porém, ocorre a diminuição dos sítios ácidos com o aumento da temperatura acima de $750{ }^{\circ} \mathrm{C}$, com isso ocorre também a diminuição da área superficial e o crescimento do cristalito (Khder et al.,2008; Khalaf, Mansour \& Mandani,2011; Alaya \& Raban, 2012).

A estabilidade térmica do óxido de nióbio (Nb2O5) é termodinamicamente mais estável que os demais óxidos de nióbio estequiometricamente, tendo propriedades físicas e química característica do próprio composto. Sua aplicação é 
amplamente utilizada devido a sua boa estabilidade a altas temperaturas, entre filtros de interferência óptica de alta qualidade, sensores, catalisadores, entre outros (Zhang et al., 2010; Lai et al., 2005).

Segundo Braga et al. (2008) a $100{ }^{\circ} \mathrm{C}$ ocorre eliminação da água adsorvida fisicamente e cerca de $300{ }^{\circ} \mathrm{C}$ ocorre a decomposição com o precursor dos ligantes de oxalato de nióbio. Mostra-se que com a elevação da temperatura acima de 300 ${ }^{\circ} \mathrm{C}$ acarreta a completa decomposição do oxalato de nióbio para óxido de nióbio, gerando uma perda de massa.

\section{Conclusão}

Através das análises dos trabalhos apresentados nesse artigo foi possível observar as aplicações através das análises térmicas e as técnicas que podem ser aplicadas, cada uma destacando em um tipo de propriedade física a ser analisada. Além da aplicação físico-química, as análises térmicas são largamente utilizadas na área industrial, admitindo um controle na qualidade de materiais. Com isto aprovando que essas técnicas sejam utilizadas em diversas áreas, como: engenharia dos materiais, engenharia mecânica, física, química entre outras. Sugere-se novas pesquisas que busquem verificar a eficiência, aplicabilidade e viabilidade de materiais com uso da caracterização dos mesmos a partir dos resultados da análise térmica.

\section{Referências}

Alaya M. N. \& Raban, M. A. (2012). Some physico-chemical properties and catalytic activity of sulfate ion supported on WO3/SnO2 catalyst. Arabian Journal of Chemistry.

Akiyoshi, M., Takagi, I., Yano, T., Akasaka, N. \& Tachi, Y. (2006). Fusion Eng. Design, p. 81.

Berg, E. A. T. (1989). Matéria-prima versus processamento. In: II ENOMAT - Encontro Estadual sobre Novos Materiais.

Braga, V. S., Barros, I. C. L., Garcia, F. A. C., Dias, S. C. L. \& Dias, J. A. (2008). Esterification of acétic acid with alcohols using supported niobium pentoxide on sílica-alumina catalysts. Catalysis Today, 133-135, 106- 112.

Castro, A. T., Perissé, E. G., Lopes, F.P., Coelho, G., Campos, R. A. \& Dutra, R. (2010). Análises Térmicas e Aplicações. <http://www.ufjf.br/fisica/2010/08/grupo-7-Analises-Termicas-e-Aplicações.pdf >.

CEPRO - Fundação Centro de Pesquisas Econômicas e Sociais do Piauí. (2005). Diagnóstico e diretrizes para o setor mineral do estado do Piauí. Teresina PI: Fundação EPRO.

Dias, L. G. (2013). Estudo do Processo de Secagem em Estufa e por Micro-Ondas de Compósitos de Argila e Resíduos de Estatito. Dissertação (Mestrado em Engenharia Mecânica). Universidade Federal de São João Del Rei, Centro Federal de Educação Tecnológica, São João Del Rei, MG, Brasil, 111 f.

Faria, R. T., Rodrigues, M. F., Esquef, I.A, Vargas H. \& Filgueira, M. J. Int. (2005). Refractory Metals Hard Mater, $23,115$.

Figueredo, G. P. (2010). Propriedades físico-químicas de argilas e de zeólitas do Estado do Maranhão - São Luís, 143 f. Dissertação (Mestrado) - Programa de Pós Graduação em Química, Universidade Federal do Maranhão.

Gaspar, M. D. \& Deblass, P. (1992). Construção de Sambaquis. In: Reunião Científica da Sociedade de Arqueologia Brasileira, 6(2), 811-820.

George, N. A., Paul, T., Radhakrishnan, P., Nampoori, V. P. N., Vallabhan, C. P. G. \& Mater, J. (2000). Sci. Lett, p. 499.

Glazier, J. D. \& Powell, R. R. (1992). Qualitative research in information management. Englewood, CO: Libraries Unlimited. 238p.

Gonçalves, C. L. (2015). Síntese e caracterização de argila maranhense dopada com estanho e nióbio como catalisador heterogêneo em reações de esterificação - Curitiba, 104 f.: il., tabs.

Young, H. D. \& Freedman, R. A. (2004). Fí-sica II: Termodinâmica e ondas. Addison Wesley.

Khalaf, H. A., Mansour, S. E. \& EL-Madani. E. A. (2011). The influence of sulfate contentes on the surfasse properties of sulfate-modified tin (IV) oxide catalysts. Journal of the Association of Arab Universities for Basic and Applied Sciences, 15-20.

Khder A. S., EL-Sharkawy, E. A., EL-Hakam, S. A. \& Ahmed, A. I. (2008). Surface characterization and catalytic activity of sulfated tin oxide catalyst. Catalysis Communications, 769-777.

Lee, S. M. (1991). International Encyclopedia of Composites, 1-6.

Luna, F. J. \& Schuchardt, U. (1999). Argilas pilarizadas- Uma introdução. Química Nova, 104-109.

Maia, L. J. Q., Martins, T. A., Gesicki, A. L. D. \& Salvetti, A. R. (2000). Caracterização Térmica de Argilas da Cidade de Costa Rica no Estado de Mato Grosso do Sul. Artigo publicado nos Anais $44^{\circ}$ Congresso Brasileiro de Cerâmica-31 de maio a 4 de junho - São Paulo -S.P. 
Research, Society and Development, v. 10, n. 1, e6510212284, 2021

(CC BY 4.0) | ISSN 2525-3409 | DOI: http://dx.doi.org/10.33448/rsd-v10i1.12284

Moran, M. J. et al. (2013). Princípios de Termodinâmica para Engenharia. (7a ed.), LTC.

Oliveira, O. M., Zandonadi, A. R., Martins, M. V. S., Carrió, J. A. G. \& Munhoz, A. H. (2010). Caracterização de uma argila de Vitória da Conquista - Bahia, por análise térmica. Artigo publicado nos anais $19^{\circ}$ Congresso Brasileiro de Engenharia e Ciência dos Materiais - CBECiMat, 21 a 25 de novembro, Campos do Jordão, SP, Brasil.

Pradère, C., Goyhénèche, J. M., Batsale, J. C., Dilhaire, S. \& Pailler, R. (2006). Int. J. Thermal Sci, p 443.

Rodrigues, D. C. (2011). Termodinâmica. Vitória - UFES, Departamento de Física.

Sales, H. B. (2009). SnO2 suportado em argila para síntese de Biodiesel. Dissertação (Mestrado) - UFPB/CCEN. João Pessoa, 88 f.

Santos, P. S. (1975). Tecnologia de argilas, aplicada às argilas brasileiras por Pérsio de Souza Santos. São Paulo, Edgard Blucher, Ed. da Universidade de São Paulo.

Sousa, A. S. (2013). Processo de fabricação e qualidade dos blocos cerâmicos fabricados na cidade de Santa Quitéria-Ce. Trabalho de Conclusão de Curso. (Graduação em Engenharia Civil) - Universidade Estadual Vale do Acaraú.

Souza, J. R., Melo, M. A., Dantas, M. J. \& Melo, D. M. A. (2000). Clarificação de efluentes da Indústria Têxtil utilizando Vermiculita Ativada como Adsorvente: Estudo Cinético e Termodinâmico. Anais do II Encontro Brasileiro sobre Adsorção, p. 365.

Werlang, M. M., Araújo, M. A., Nunes, S. P. \& Yoshida, I. V. P. (1998). Miscibilidade de blendas de poliestireno com polímeros de silício. Polímeros. 8(4).

Zhang, D., Zhou, C. H., Xiang, C. L., Tong, D. S. \& Yu, W. H. (2010). Synthesis of clay minerals. Applied Clay Science 1-11. 